\title{
Integrity \& Trust: The Defining Principles of Great Workplaces
}

\author{
Mrs Amena Shahid \\ College of Business Administration \\ Prince Sultan University \\ P.O Box 53073 Riyadh 11583, Kingdom of Saudi Arabia \\ Tel: 966-54-599-8831Ｅ-mail: amena.shahid@gmail.com
}

Dr Shahid. M. Azhar

Deputy Director of Development and Marketing for Center of Excellence Research in Engineering Materials (CEREM)

King Saud University

P.O. Box. 800 Riyadh 11421, Saudi Arabia

Tel: 966-14-695-441Ｅ-mail: sazhar@ksu.edu.sa

Received: May 21, 2013

doi:10.5296/jmr.v5i4.3739
Accepted: September 24, $2013 \quad$ Published: October 1, 2013

URL: http://dx.doi.org/10.5296/jmr.v5i4.3739

\begin{abstract}
Understanding the role of integrity and trust at an individual and organizational level are metrics to build the absolute standard of what a great workplace is. At its most basic level integrity, respect and trust is the assurance people have that one will certainly act in their best interest, never knowingly committing actions that might harm them. There is no particular activity that will build integrity; rather, you institute both over time by consistently exhibiting a number of behaviors and conduct. Integrity, as a measure of coherence and consistency, is key to establishing and sustaining trust. We trust those who are honest and consistent in their actions, who fully acknowledge valuable information, who are willing to deal with tough issues, and who are open about their ambitions and motives. At the corporate level it takes individuals of integrity to cultivate a consensus around mutual values. As this consensus builds, the corporation fosters a culture of Integrity. A culture of integrity creates a highly
\end{abstract}




\section{Macrothink}

Journal of Management Research ISSN 1941-899X 2013, Vol. 5, No. 4

respected work environment; it impacts the quality of corporate administration; and it provides a foundation for worthy long-term financial performance. This paper focuses on the issues of the integrity of the individual and its importance at the corporate level in creating a culture of integrity and trust.

Keywords: Accountability, Long term financial performance, Great places to work, Trust, Commitment 


\section{Introduction}

This paper represents a significant block of Integrity and Trust and thus attaining a strong organizational culture that affects business performance and help organizations and its leaders to understand the trends and issues related to it as well as come up with creative and valid strategies to enhance their organizational performance.

Trust underpins and influences the quality of every affiliation, connection, project and application with which we are engaged. Trust is the essential prerequisite on which all authentic business success depends. Contrary to what many people think, trust is a factual asset that can be devised. It can also be crippled. It takes time to repair trust and, in order to achieve this; organizations require envisioning and communicating differently. Higher trust offers higher savings in cost, time and quality, as well as improving relationships. In the business world trust is pertinent and critical as a mechanism for economic and political success because there is such a high scarcity for it. During the progression of this paper we will analyze a few of the best practices adopted by some of the Best Workplaces. In particular we aspire to attain a deeper insight into what it is they carry out to achieve and cultivate such high levels of trust within their organizational structure and how successively may undertake as an incentive for their revival from the current recession. CoveyLink Worldwide (2006) speaks of the importance of trust because trust always affects the outcomes in terms of speed and cost. If there is a lack of trust, the speed on the transaction will go down and the cost will go up. In short, trust has a favorable impact on the economics of the relationship; trust pays a dividend in terms of speed and reduced cost.

Scholars of organizational behavior and human resource management have paid extensive attention to the subject of integrity. In addition leadership theorists and researchers have found that integrity is a central trait of effective business leaders (Bass, 1990;Kirkpatrick \& Locke, 1991;Yukl \& Van Fleet, 1992). Integrity is the authentication of a person who displays strong moral and ethical principles at work. People who demonstrate integrity derive others to them because they are reliable and dependable. They are ethical and can be relied on to perform in reputable and righteous ways even when no one is observant. It is those traits of an individual that are frequently accommodating, compassionate, lucid, candid, and ethical. The trait of trust is closely paired with integrity. While the definition may seem ambiguous, we designate individuals with integrity as an individual that we can depend on to do consistently what is "just" and what is anticipated of them. They are reliable and predictable in dealing with others and with issues, and they are supporters of what is fair, just, and respectable.

In the Turknett Leadership Character Model, developed by psychologist Dr. Robert Turknett, integrity is the foundation of the model, and without integrity, no leader can be successful. The Turknett Leadership Group notes that individuals of integrity will not twist facts for personal advantage; they are willing to stand up for and defend what is right; they will be careful to keep promises; and they can be counted on to tell the truth. In their model, integrity is the foundation of leadership and it involves a careful balance between respect and responsibility. (Turknett, n.d.). 
At the corporate level, integrity associate to the culture, administration, and leadership principles. A culture of integrity has to commence at the top and be perceived in the conduct and activities of the executives. The leadership of the enterprise must develop an accord around mutual values. As Kouzes and Posner (2002, pp. 79-80) point out, the development of shared values improves the work environment and productivity:

- It strengthens personal effectiveness, corporate loyalty, and ethical behavior

- It fosters team work, corporate pride and consensus

Corporations that have these values surpass other firms by a wide margin in terms of earnings growth, job formation, stock price and profitability. As Quigley (2007) has pointed out, the culture of integrity may be far more important than the starting salary in one's quest for personal and professional fulfillment. He notes that corporations with a culture of integrity:

- Offer support to employees through colleagues and processes in place; consultation with other is seen as a strength rather than a weakness, and

- Supports a work-life balance as it reduces job stress, balances one's perspective, and contributes to job satisfaction (Quigley, 2007, p. 15).

Ranked integrity organizations are characterized as organizations that are collaborative, practical, creative, crystal clear, with high employee morale, appreciative customer loyalty, and strong partnerships. They frame teams and establish value. Studies have shown that corporations with a culture of integrity tend to have governance systems with higher extrinsic ratings and higher characteristic of earnings. They tend to be good places to work, aggressive in their markets, and provide higher, more anticipated returns to investors.

\section{Integrity and Trust Dilemma}

A deficiency of trust is indexed as the number one problem confronted by leaders today. Within each category of life, there appears to be an ethical failure among leadership. For example, the corporate world has Enron, WorldCom, Arthur Anderson, Tyco, Health South, and even the American Red Cross. According to several studies, the integrity dilemma is not only tormenting our leaders, but also our culture.

A MoodysEconomy.com survey published in January 2009 discovered that business confidence had reached record lows (Harned.P; 2009). According to a survey by the American Management Association (AMA) in 2002, 76\% of managers listed ethics and integrity among their company's corporate values, and yet 32\% admitted that their company's "actual practices did not match their public ethics statements” (McCollum, T; 2002). BP has been blocked from seeking new contracts with the US government because of the oil company's "lack of business integrity" during the Gulf of Mexico oil disaster (The guardian ; 2012)

Despite these distressing statistics, employees value integrity and honesty as a key Component for leadership. According to the research, followers desire for their leaders to be people they can trust - full of integrity. One survey named integrity the most important 
characteristic for CEO's of energy companies (Capgemini, U. (2005).According to the research done by Kouzes and Posner (2007) which spanned twenty years, a variety of countries around the world, and over 75,000 respondents - the number one desired leadership characteristic was honesty. This is important research because it is constant over time and consistent across countries, cultures, and organizations. Followers not only desire, but also want to know that their leaders are truthful, moral, and full of integrity.

Not only has the lack of attention to fundamental integrity (individual, company, and system) resulted in the seeming proliferation of "bad apples" in corporate America, but the whole "barrel" also seems increasingly tainted, lacking in adherence to any kind of code that might breed trust, rather than deception, fraud, and malfeasance. Integrity at the individual level presumably provides for the kind of soundness and honesty that results in authenticity of behavior, being true to one's own beliefs and standards (personal codes) as well as to the numerous corporate mission statements and codes of conduct that now mention not just one but a whole range of stakeholders (Kolk, van Tulder \& Welters, 1999).

\subsection{Devising Trust \& Honesty; A Dignified Conquest}

Honesty and trust are key ingredients in developing an organizational culture that becomes the talk of the town as one of the preferred place to work by the current and potential employees. Trust is a decisive factor in establishing credibility. The credibility is at the center of ones competency to influence others and provide strong leadership. The most capable leaders utilize the words like sincere, truthful, trustworthy, reliable, principled, and genuine to symbolize the characteristics of the effective leaders.

An employee searching for a great place to work is worth the effort at an individual level. Capitalist examining to identify a company that produces positive, sustainable long-term financial success is also a significant effort in terms of establishing business ventures. And for a leader, a great workplace is worth the effort because they are the ones who institute and sustain the creation of great workplaces.

Employees in the leading organizations communicate that their colleagues and immediate supervisors invest their time and efforts in creating the distinctive situations and resources for their teams. Yet their leaders are seen as the ones who actualize the ethics and responsibility that make the difference in the quality of the workplace experience.Constructing a culture in which employees can say, "this place is terrific" requires that leaders and managers throughout an organization base their affiliations with employees in behavior that advocate and progress trust. Consistency between the communication and behavior of leaders develops their validity in the perception of employees. Managers who are treated with consideration by superiors will in turn be adequate to share that respect with employees by advocating their professional development \& seeking their judgment.

Studies show that productivity, income, and profits are positively or negatively collided depending on the level of trust in an organization. Trust can be created or destroyed through personal perceptions and behaviors. Trust means assorted things to diverse people. It's forecasted on who we are and how one is raised and is shaped by ones experiences and 
perceptions of other's behavior. Repairing trust has become a foremost priority for companies that are looking to escape the negativity that has become prevalent in many organizations. An egocentric, "What's in it for me" approach deprives an organization of the best that employees have to offer. When employees recognize that an organization-or its leaders-are deficient in being accessible, employees become unwilling to devote any optional energy or make any assurances to their organization's prosperity beyond the absolute minimum. Absence of trust creates sarcasm, conviction, and apprehension that lead to leisure time theory and generally low energy and productivity. When people don't rely in their leaders, they don't come toward something; they pull back and withdraw instead. They apprehend rather than contribute.

\section{The Five C's of Trust}

Managers and leaders deduce that people are paid to work hard so they should work hard. Well it is a good assumption to a point but it also critical for the leaders to understand that certain needs are to be met for people before they will give that discretionary effort and work hard with commitment for an organization. Restoring trust with the people can be attained by executing the following five C's: Clarity, Compassion, Character, Contribution, Connection, Consistency. Trust is not a benefit that comes wrapped up on any ones doorstep. It must be established and earned and the people will believe in their organizations and leaders ability, consistency and integrity to deliver.

\subsection{Clarity}

Clarity is the exclusive value added investment that an organization can focus on. It illuminates the path for coordinated action, mobilize potential of the teams and staff throughout the organization and encouraging the trust and determination of stakeholders.

This element brings a leadership style that promotes what they know best and thus leading their and organization future that all understand and accredit. Clarity applies to 4 key areas. Whom doe we serve? $\Rightarrow$ What is our core strength? $\Rightarrow$ What is our metric to achieve focus? $\Rightarrow$ What actions can we take today? The above 4 areas can be achieved by dedicating the time to define essentials and thus focus on what matters, by recognizing and appreciating the ones who can become role models for others and lastly to process oneself to focus on the material that is genuine and applicable.

\subsection{Compassion}

Compassion is a difficult element to demonstrate because it involves figuring out how to care about the interests and needs of someone else as much as oneself. In The Art of Happiness (1998) the Dalai Lama defines compassion as "a mental attitude based on the wish for others to be free of their suffering, associated with a sense of commitment, responsibility and respect towards the other..." Many see compassion as a weakness, but real compassion is the distinction that converts knowledge into wisdom. A wise leader applies compassion to perceive the needs of those he leads, and sensibly determine the course of action that would be of greatest benefit to the individual as well as the team. 
"Bill [William Hewett] and Dave [David Packard] could be gruff and demanding but were seen as compassionate at heart. They agonized over layoffs and, according to company lore, would apologize for angry outbursts. They created one of the most humane workplaces in the United States. The founders also served as models of integrity. HP products were expensive but they were dependable. Wall Street could trust the numbers that Hewlett and Packard presented to analysts.” (Criag, 2008). Howard Schultz (Starbucks) “explains how [employee] meetings help him lead a fast-growing \$ 6.4 billion global company with 90,000 employees, 9,700 stores, and 33 million weekly customers. 'People aren't interested in how much you know... It's how much you care.'

( Meyers, 2005). Your team and your bosses will know who you are in your soul, what kind of people you attract, and what kind of performance you want from everyone. Your realness will make you accessible; you will connect and you will inspire. You will lead.”

(Welch, 2007). It's often been said, “People don’t care how much you know, until they know how much you care.” All organizations should think of building eminent performing team which are built on high degree of trust by leading with compassion.

\subsection{Character}

A lot is discussed through significant books and research scholars about the role of the character of an organization or a leader and what it really represents. Whether one is operating an organization or a store, delegating a project or executing a community event the perspective of one who leads towards the team or group effects what they do and what they think of the leader or an organization. A person who positively leads from character doesn't need the title, authority or power because people will passionately join that person in their quest of a goal. These people are going to be committed, motivated and ardent about pursuing the goal because they trust you. It all comes down to people accomplishing things because they want to as contrary to being forced to. Character represents who you really are. It's the central fiber of your being. It is your inner self in action. It reveals what you are truly made of, it's your substance. It sets one apart, creates trust, advocates excellence, augments influence and assists one to sustain.

\subsection{Connection}

Connect to engage has been said so many times and that valid leadership is determined by ones ability to motivate and influence others. The great barrier confronted by many is to comprehend how to effectively inspire and influence the whole team comprised of exclusive individuals. The one-word answer is simply to - CONNECT! Leaders, managers and supervisors must devote the time in each and every one of their team members to get to know more about them - to establish a connection based on trust, honesty and respect. This personal and professional connection will draw the management and their team together, to work more adequately to improve efficiencies and increase production and profitability. The prospect of leading a team that is so well connected is truly exciting. If an employee is engaged, it means that he feels he has a personal stake in the outcome - an authentic desire to contribute to something larger than himself, something even more important than monetary gain. Top 
leaders understand that in order to connect with their workforce, they need to leverage the power of emotion. Only by connecting with the individual, can a leader create a powerful team consisting of employees who are personally committed, and emotionally/physically engaged.

\subsection{Consistency}

Consistency at workplace is the last C's of building and maintaining trust among your employees. Being consistent in ones practice leads you towards a trustworthy working relationship and one way to implement this practice to verify that all team members are on the same page is to distribute documents outlining the companies' policies and guidelines. Consistency is hard to achieve but it does scores high points because it structures and supports employee's expectations. Due to hectic workplaces of today keeping consistency can present a challenge but at the same time a workplace having consistent policies, procedures and code of conduct has its marvelous benefits as well. There can be number of reasons why at workplace should be a goal to determine how much effort one should assign to establish consistency? Organizations where consistency appears employees feel more organized than where things are constantly changing. By making things consistent, one can allow employees to dedicate more of their time to the completion of their actual job duties, likely leading to an increase in productivity and thus making it easier for the employees to understand the duties associated with their jobs as well as your expectations for them.

\section{Is it Time to put Trust and Integrity back in the Workplace?}

During defiance economic times the fragile relationship between employees and employers is harshly tested. Executive making decisions during the economical downturn may affect their employees drastically. The current recession has curtailed 2 significant principals of business environment - trust and integrity. The disconnection between employers and employees over trust and respect claimed voluntary turnover in organizations.

What has caused this decay in trust? Extensive deception at the workplace and organizations mishandling employees to executives committing corruption and thus taking credit for others work eroded trust over time. Many leaders in all sectors failed to envision the power behind illustrating high integrity and being trustworthy. They also failed to conceive how it affects business results and finally they failed to understand that cultivating and conserving trust with their employees and teams is a major compelling leadership tool than any vital marketing or sales plan.Integrity and trust promotes debate, authorizes innovation and welcome the changes which leads an organization's business. Trust requires one to communicate openly with the management, teams and colleagues; to share equally the key information about both successes and challenges, and to learn and grow from one's own experiences. A workplace where fear is altered with compassion and trust, an environment where learned and refined leaders establish collective and respectful environment and thus team member work at their highest potential is a leading culture of organizational trust. In order to have a credible culture of integrity and trust the following is suggested to be applied. 


\subsection{Animate the principles}

Match actions with words. Live up to the values one advocate. Inspire people through leading by example. Exercise and encourage adjustment with the values daily and send clear indications about what the values are. Make ethics precedence. Model righteous behavior and support those who maintain standards.

\subsection{Communicate Connect and Correspond}

Boost clear communication. Keep employees abreast and concentrate issues when one monitors them. Create a discourse. Pay attention, Connect and involve people at the principal of a project or decision as early as possible. Appreciate people's contributions and opinions. Disseminate the importance of ethics and integrity, along with mutual perception and values. Supply apparent and consistent communication to key stakeholders.

\subsection{Disclose the Reality}

Be candid. Elude hidden agendas. Be easy, uncomplicated, and consistent. Share what you are acquainted with when you recognize it.

\subsection{Be in integrity}

Make good on your promises and commitments. Be realistic. Don't over commit. Act what you say you're going to do. Accept accountability for the conduct and act ethically.

\subsection{Be authentic}

Engage in honest conversations. Be credible. Be who you say you are. Demonstrate company values through thoughts, words, intentions and actions. Bring words and actions into alignment.

\subsection{Be Obligated}

Admit mistakes. Be clear and be apparent. Acknowledge information as needed. Acutely communicate facts to establish trust and credibility with stakeholders.

\subsection{Admire the individual}

Foster mutual trust and respect. Be inclusive and show compassion. Endorse and honor people's feelings and concerns.

\subsection{Share information}

Keep employees acquainted and direct issues when they are perceived. Note that outcomes may change, and provide appropriate feedback. Involve people at the fundamental level of a project or decision whenever possible. Engage those who are or could be influenced. Sharing of information within and between teams composes dialogue, encourages cooperation, and assists frame community over time.

\subsection{Determine the right thing}

Adequate declaration holds the impact of values, ethics and reputation on the bottom line: Integrity driven companies are the most successful. Companies that fail to look after the 
reputation aspects of performance ultimately suffer financially. Companies that are great places to work are more financially successful. Organizations with high trust benefit from increased profitability, market value, and lower costs.

Leaders should create a culture of trust simply because it's the right thing to do. Adam Smith, author of The Theory of Moral Sentiments (1759), believed that virtues like trust, fairness and reciprocity are vital for the functioning of a market economy. Concede the significant costs of shattering trust, compromising reputation, and giving up ethical standards. Creating a trust culture takes commitment and action. Leaders who adopt to trust, value, respect, and empower their people are rewarded with motivated and productive people and greater profitability. In a spirit of cooperation, participation, dialogue and hope, a cultivation of trust can be attained.

\section{Trust and Integrity Is Forever}

Each person who has faith in you will disseminate the word of that trust to the colleagues, and word of your character will spread like a blaze. The appraisal of the trust others have in you is highly significant. For entrepreneurs it channels the message that investors are willing to trust for monetary collaboration, for employees it means the supervisor is willing to trust for increased accountability and growth opportunities, for companies it means customers that trust granting more business and at an individual level it means having a fleet of associates that are amenable to go an additional mile to assist and support because they understand that acclaiming you to others will not in any condition will bring damage to their own reputation of integrity. Yes, trust and integrity are forever because the value of both others have in you drives further anything that can be measured as it brings along with it infinite opportunities and boundless possibilities.

\section{Conclusion}

Trust must be treated as precious, highly admired, and a cherished organizational trait. Trust is an extremely substantial commodity to any affiliation. A point that needs to be promoted, is that trust is a dainty property of human relationships, in that is powered far more by conduct than by words, it may take time to constitute, but is can be abolished very quickly.

Integrity is imperative to personal success and for expanding leadership skills. Individuals that have integrity build trust in their relations with others; they become precious and are respected as friends, colleagues, mentors, and supervisors. They are respected and counted on to do what is right. They are able to balance dignity and accountability, and they are able to share their values with others.

At the corporate level, it takes individuals of integrity to foster a harmony around mutual values. They must be able to converse these values blatantly as well as live the values they advocate. As this concord builds, the entities develop a culture of integrity. This culture impacts the strong working relationships within the company and creates a highly valued work atmosphere. Employees are motivated and innovative, take pride in their work, and enjoy their affiliations. 
The culture of integrity also impacts the behavior and administration of the leadership team and the quality of the corporate executive system. Corporations with a culture of integrity aim to be leaders in their industries; they aim to exceed other firms and turn in stable and strong long-term financial performance. They are valuable firms to work for, to work with, and to own.

\section{References}

Bass, B. M. (1990). Bass and Stogdill's handbook of leadership. The Free Press New York, NY.

Capgemini, U. (2005). New survey of energy CEO's finds integrity is most important component of executive leadership. Retrieved from: http://www.allbusiness.com.

CoveyLink Worldwide. (2006). How Do You Measure Trust?. Retrieved from: http://www.coveylink.com/training-and-consulting/consulting-f.php.

Harned, P. (2009). Leadership integrity: Weighing nonprofit workplace ethics. Retrieved from:

http://www.christianleadershipalliance.com/outcomes/2009/summer/leadershipintegrity.html

His Holiness the Dalai Lama, \& Howard C Cutler, M.D. (1998). The Art of Happiness: A Handbook for Living. New York: USA: Penguin Group Inc.

Johnson Craig. (2008). The Rise and Fall of Carly Fiorina: An Ethical Case Study. Journal of Leadership \& Organizational Studies, 15(2). http://dx.doi.org/10.1177/1548051808320983

Kirkpatrick, S. A., \& Locke, E. A. (1991). 'Leadership: Do traits matter', Academy of Management Executive, 5(2), 48-60.

Kolk, Ans, Rob van Tulder, \& Carlijn Welters. (1999). International Codes of Conduct and Corporate Social Responsibility: Can Transnational Corporations RegulateThemselves?. Transnational Corporations, 8(1), 143-179.

Kouzes, J., \& Posner, B. (2007). The leadership challenge. Jossey-Bass, San Francisco.

Kouzes, James M., \& Posner, Barry Z. (2002). The Leadership Challenge, Jossey-Bass San Francisco, CA.

McCollum, T. (2002). Ethics escapes corporate practice. Retrieved from: http://www.allbusiness.com

Meyers, William. (2005, October 31). Conscious in a Cup. U.S. News \& World Report, 1-3.

Quigley, James H. (2007). Trust - An Essential Asset: Creating Individual and Corporate Value. The Raytheon Lectureship in Business Ethics, Waltham: Bentley College, pp. 1- 24.

Suzanne Goldenberg. (2012 ).BP suspended from new US federal contracts over Deepwater disaster. Retrieved by: http://www.guardian.co.uk/environment/2012/nov/28/epa-suspends-bp-oil-spill. 


\section{Macrothink}

Journal of Management Research ISSN 1941-899X 2013, Vol. 5, No. 4

Turknett Leadership Group. (2009 ).The leadership Character Model online. Retrieved from http://www.leadershipcharacter.com/model.php.

Welch Jack. (2007, 23 January). Get Real, Get Ahead. Business Week.

Yukl, G. A., \& Van Fleet, D. D. (1992). Theory and research on leadership in organizations. In M. D. Dunnette \& L. M. Hough (Eds.), Handbook of industrial and organizational psychology, 3, 147-197. Palo Alto, CA: Consulting Psychologists Press. 